\title{
How can we help? An educator's perspective on the Situation Table Model in Ontario
}

\author{
Stan Baker*
}

\begin{abstract}
Marginalized people in our communities experience social and educational services in silos, which can often lead to crisis and increasing risk of harm. Complex situations with multiple risk factors cannot be addressed by any single agency on its own. Collaboration between agencies is often challenging. Risk-driven Situation Tables provide clear structures and supports for communities to respond quickly to situations of acutely elevated risk with rapid responses to connect marginalized people to services. School Board participation in Situation Tables is essential because: a) educators may not even be aware of other risk factors in a complex situation; b) truancy is not just a school problem and is an indicator of other risk factors; and, c) the complexity of student risk factors beyond the mandate of School Board requires collaboration with multiple sectors. In this article, the author provides evidence in support of these arguments through several real-life examples of these types of situations, and offers his educator's perspective on this social innovation, gained from his direct experience as a Table Chair in his final year of a 31-year career in education.
\end{abstract}

Key Words Acutely elevated risk, risk driven, situation table, collaboration

Journal of CSWB. 2016 Aug;1(2):16-20

www.journalcswb.ca

\section{INTRODUCTION}

It looked like a very ordinary meeting of community agencies, yet it was anything but ordinary. On a Tuesday morning in the fall of 2015, twenty people representing community agencies met together. They included staff from community and social services, education, youth justice, probation, adult mental health, youth mental health, victim services, police, hospital, housing transitions, family violence prevention, and community counselling. They listened intently as Pauline from the police (all names are fictional) presented a situation that she had determined before the meeting to be one of acutely elevated risk. The situation held the potential for agency involvement from police, child protection, education, and mental health. The youth (female 12-16) had been missing school and skipping classes in her new school on the days that she did attend. She had a history of aggression and violence in a previous school, and her single mom had reached out to family to take the youth. The violence was now escalating at home in assaults against her aunt and uncle, since they were now providing shelter and what they hoped would be a new start. The youth had become involved with negative peers and was the victim of physical violence. She was abusing drugs and reported experiencing anxiety and depression.

The staff around the table responded with questions for clarification that were answered by Pauline. The Chair then asked everyone if this was indeed a situation of acutely elevated risk (McFee \& Taylor, 2014). When everyone agreed that it met that threshold, the discussion moved on to identifying the list of risk factors and determining who should be involved in a door-knock intervention (McFee \& Taylor, 2014). Agency staff arranged to meet and bring the services to the individual or family, leading with the question, "How can we help?"

It is vital that School Board representatives sit at these Situation Tables, a relatively new model for multi-sector collaboration and rapid intervention that is taking root in Ontario and across Canada (Russell \& Taylor, 2014). School Board staff cannot help if they are not aware of the multiple risk factors that affect students. "You don't know what you don't know" is illustrated time and again at Situation Tables when a variety of social service agencies bring different lenses to bear upon complex situations. School Boards need to be participants at Situation Tables in order to be part of connecting the right services to students and families in a timely manner. The risk factors determined in the "what you don't know", coming from different agencies' lenses at the Table, assists School Boards when dealing with many situations involving students with complex needs.

Secondly, community agencies are joining School Boards in recognizing that missing school is in itself a significant risk factor. Truancy is often the tip of the iceberg 
and a strong indicator of other risk factors (Nilson, 2014). Many of those risk factors like poverty, housing, or family mental health, are beyond the mandate of a School Board. School Boards can utilize many internal resources if the student attends school. The challenge for schools is getting the students into the building. At the Situation Table, social service agencies work with School Boards to address truancy, along with other multiple risk factors. Situation Tables that include School Board representatives can connect students to appropriate social services in the community which, in turn, can directly impact student attendance and student achievement.

Thirdly, School Board involvement in a risk-driven Situation Table is important for the marginalized students whose situations are complex and already known to the school. Services for special education needs and mental health needs are present in schools, yet there are situations in which the numbers of risk factors make it challenging for schools to address all of these alone before a crisis or harm is caused. Schools need multi-disciplinary responses and the assistance of agencies to connect students and families to services. Like any other community organization, a School Board is not able on its own to address the multiple risk factors that can lead to harm or negatively impact community safety.

The extraordinary part of the ordinary looking meeting that Tuesday in the fall of 2015 was that there were no silos between agencies, and the help that was arranged came from a team that was firing on all cylinders. The staff all came from agencies in Northumberland County, located on the north shore of Lake Ontario, between Toronto and Kingston. Northumberland had a census population in 2011 of approximately 82,000 people in a rural area of 1900 square kilometers (Wikipedia, 2016). The largest urban centres are Cobourg (pop. 18,000), Port Hope (pop. 16,000), and Brighton (pop. 11,000). The extraordinary meeting came out of a collective interest in preventing a crisis based on a risk-driven response, rather than an incidentdriven response. A group of agencies had set up a new form of collaborative intervention known as the Situation Table Northumberland.

Marginalized people have firsthand experience of the effects and frustration of "silos of services" in which they are lost in the shuffle and risk factors are left unaddressed. At the same time, front-line service agency staff members also face the exasperation of complex situations with multiple risk factors that a single agency cannot address on its own. While everyone works to prevent harm and improve community safety, it is often challenging to collaborate to address these complex risk situations. The following are a few stories from the first year of working with the Situation Table in Northumberland County, and each highlights the positive impact that a risk-driven Situation Table can make with marginalized people, and within and across the social service agencies in any community.

\section{BACKGROUND}

A year and a half of planning and training led to the first meeting of the Situation Table (often called a Hub or Hub Table) earlier that spring on May 15, 2015. The model used was based on the work developed by Community Mobilization
Prince Albert (CMPA) in Saskatchewan. "It is the component that provides immediate, coordinated and integrated responses though the mobilization of resources to address situations facing individuals and/or families with acutely elevated risk factors, as recognized across a range of service providers" (BPRC 2013).

By March 31, 2016, less than a year later, the 20 agencies represented at the Situation Table Northumberland had already dealt with 65 situations in which there were:

multiple risk factors; multiple agency involvement required; concerns about the risk of harm; and, significant community interests in addressing the acutely elevated risk.

Through these situations, a total of seventy people had been helped by being connected to services or by getting information about services available to them that would lower their risks.

The Situation Table Northumberland broke down the traditional silos of operation by:

active collaboration through positive working relationships, without the blame game, as a result of the highly structured table process;

- connecting marginalized people to multiple services all at once;

- providing system navigation through the existing service silos;

- building and sustaining stronger working relationships outside of the Situation Table Northumberland process to make the services a well-oiled machine firing on all cylinders.

\section{A Prototypical Situation Table Intervention}

"How can we help?" was the question that led off the conversation at the door knock back in the fall of 2015. The intervention team consisted of: Victoria from Victim Services; Sam from the School Board; Cassie from children's services; Pauline, from the police; and Mandie from mental health. Pauline had taken the lead and arranged to meet with the youth (we'll call her Mary) at a neutral location, along with her family. The door-knock team helped Mary and her family address every question that came up. Each person on the door knock was able to speak to the risks, and was able to introduce ways that could reduce those risks, while also strengthening many of the necessary protective factors. Sam contacted the school to see that Mary was connected to some positive peer groups and to activities during times when she had been known to skip classes. Cassie described the in-home support available. Mandie made counselling available, and Victoria arranged to meet with the family after the door knock to go over specific services that she could offer. As everyone was about to leave, Mary's aunt spoke up with some emotion and thanked the team, because "everyone is here in the room talking with us at the same time like we had always hoped." The active collaboration of the Situation Table was needed in order to address the multiple risk factors for Mary and her family. No one agency could have addressed all of these factors on its own. 


\section{Collaboration Spreads Beyond the Table}

Active collaboration changed the way services work together. In another situation, a door knock was arranged by Paul from Probation Services, for a client who had experienced difficulty in complying with his conditions. When the client, Bob (age 20-30), first came into the room, he initially showed his reluctance to be there with Henry from housing, Mandie from mental health, Victoria from victim services, Pauline from police, and Paul. As happens at every door knock, Paul opened by asking Bob, "How can we help?" Once Bob understood the purpose of the gathering, he sat down and started crying. "All you people are here to help me?" he asked. As the conversation unfolded, different agency representatives took on pieces of what needed to happen to help Bob. Victoria explained how she could help Bob deal with the victimization he had experienced. Bob had never seen himself as a victim before and was, in the words of the Pauline, "blown away by the people sitting around the table." Bob was connected with the services he needed to prevent further harm to himself or to others in the community. When Paul reported back to the Situation Table the following week about how well the door knock had gone, he said that, "As a Probation Officer, this is the way I've always dreamed of working with the police."

Working as a team with a shared purpose of helping to alleviate risk has reduced the sense of "competing processes". In a planning discussion before a door knock, Sam from the School Board was able to share that a recent incident involving Barb, an older teen, had already led to a Stage 1 VTRA (Violence Threat Risk Assessment) (Cameron, 2016) the previous week due to threats, aggression, suicidality, and drug abuse. Sam was planning a more comprehensive risk assessment Stage 2 VTRA to do some longer term planning. Mandie from mental health was able to talk about her involvement with the same client, and Susan from the local shelter informed the door-knock team that Barb was staying at the shelter. Sam asked the rest of the team to join the school's risk assessment meeting. The decision was made to combine the two processes, since many of the same agencies would be represented. Susan arranged to have everyone meet with Barb at the shelter. Although Barb became very agitated and shut down as the meeting progressed, the door-knock team was grateful to see how Barb had connected with Susan and other staff from the shelter. Barb's most immediate risks were addressed by having shelter, and through counselling. Barb was able to get good food every day, and she began to establish positive routines. Her school credits and courses could be addressed once the main risk factors had been alleviated. The school process was rolled into that of the door-knock intervention, since the risk factors concerned things outside of the school and outside of the school's ability to address. The respectful working relationships and a strong sense of team prevented professional egos from getting in the way of reducing the risks. There was no blaming other organizations for what had or had not been done, nor did anyone tell each other how to do their respective jobs. Each service agency had a part to play, and each stepped up to do it together, in order to reduce the risks to the youth. It was once again evidence of a well-oiled machine firing on all cylinders.
Helping Our Common Clients to Navigate the System The Situation Table has had benefits far beyond the weekly meetings by also working as a well-oiled machine away from the table in day-to-day work, by increased access to resources and through help in system navigation. For example, on a Saturday afternoon in October, the police responded to a call about a suspicious person in a wooded area outside of town. Upon investigation, the police found John (male 16-21) who had been living in the woods for about four weeks since he'd been kicked out of his family home. Police secured temporary shelter for John for the weekend and met him at school on Monday morning. The school had been unaware of the student's living situation, since he had still been attending regularly. Because of previous work at the Situation Table, Pauline from the police was able to contact a local housing shelter and the school in order to address the needs of this youth. Pauline then drove John to the shelter, where she said that, "It felt like we were dropping off one of our own kids with people we could trust." The shelter arranged for temporary accommodations and then eventually moved John into his own place. He continued to attend school in the new location and has been doing well. None of this could have been navigated in just two days without the positive working relationships and strong connections that had developed at the Situation Table.

System navigation is simple if people know whom to call. Sam from the School Board received a call from Pauline from the police about a case conference. Sam did not know the family involved, but he did know Pauline from the Situation Table. Sara (female 30-40) was staying at a women's shelter and had given consent for Cassie from children's services, Pauline and Sam to attend a meeting together with her. Sara had been the victim of domestic violence and had a number of concerns that she wanted to address with the Pauline, Cassie, and Sam about her three children. Sara wanted to ensure that the school bus did not stop for anyone after picking up her two children, before their safe arrival at school. She also had a request for an accommodation for one older child heading off to high school. Since Sam could navigate the school system, he was able to do that with two phone calls to two school principals immediately after the meeting. Both school officials expressed appreciation for the information, and both committed to follow up on the request. Sam's role was one of navigating the school system.

System navigation happens even without identifying the name of a person or situation to the whole group at a Situation Table meeting. In this example, it became clear very quickly one week that even without a person's name, at least two people recognized the situation. A woman (aged 70-80) had been calling police repeatedly for what she thought were people breaking into her house. The frequency of the calls was increasing. In discussions to determine whether or not this was a situation of acutely elevated risk, the Situation Table Northumberland decided that there were other services that needed to be involved first, recognizing that some key calls had not been made. Without any identification of the individual or address, but easily recognizing that they were talking about the same individual, Connie from Community Care informed the table that she was not aware that the Pauline from the police was involved. Similarly, Pauline indicated that she did not realize that Connie was involved with this person. 
Connie suggested that they talk after the Situation Table meeting. Connie and Pauline met and were able to address the risk factors together. The individual of concern did not come back to the Situation Table, and the necessary connections were made outside of the formal structured process.

\section{Building Lasting Collaboration Into the System}

As these examples consistently illustrate, outside of the Situation Table, system navigation is enhanced by the working relationships that are developed across various sectors that work to address situations, and this is particularly valuable to those of us who work in education. In one more situation, a principal contacted Pauline from the police about Judy (age 13-17) who was truant and was abusing alcohol. Judy's mother had called the police for service repeatedly when things were in crisis, but she would then often refuse the assistance offered. The attendance counsellor from the school had spoken with Pauline, who spoke with Judy's mother, who refused the offered help. After yet another incident, Judy's mother finally called the school staff to ask for help. The attendance counsellor and Pauline encouraged Judy's mother to come to the school for a meeting. Pauline was able to arrange a meeting between Judy and her mother and school staff, the school attendance counsellor, Victoria from victim services, Mandie from mental health, Cassie from children's services, and Malcolm from youth mental health. The initial meeting at the school focused on safety planning at home and at school. Judy's mother was offered counselling, which she accepted. Pauline arranged for a safety check visit to the home. A second meeting was set up to assist Judy and her mother deal with their respective mental health needs. Schools alone can only address student needs within the limits of an educational system. In this situation, the school could not have addressed the parent's mental health needs the way that this team of Situation Table participants was able to do.

\section{CONCLUSIONS}

\section{Concluding Thoughts from a Career Educator's Perspective}

A strong purposeful sense of team has developed at the Situation Table Northumberland in ways not anticipated by those who weekly sit at the table. Pauline from the police observed that, "The Situation Table is like a dream come true. These are the ways I have been trying to work as a front-line officer for years, but I was not able to do it. Now, I see no other way to do this without the Situation Table. We have to change the way we do things together. When people are in crisis, involving the police means it's gotten really bad. We need to work together to make sure I'm never involved."

Stories like those above show the positive impact that a risk-driven situation table can have in connecting marginalized people to needed services in a timely fashion, whether at the table itself, or through the resulting collaboration that extends to system reform. Community collaboration through a structured process, and proper training and the well-disciplined experience at the table, enhances front-line staff cooperation beyond the Situation Table. As Mandie from mental health said at a recent meeting, "It really feels like you are doing something worthwhile, something productive when you come to the Situation Table."
The Situation Table Northumberland has now had a year of working together to connect people with services in acutely elevated risk situations. At the same time, the participants at the Table are learning how to collaborate in an entirely new way. With increased awareness of the possibilities, and with a shared openness to considering a risk driven way of collaborating, educators and their partners across the province and the country can add to, and build upon, the promise of Situation Tables.

School Boards have a vital role to play at Situation Tables. You won't know what you don't know unless schools are part of a collaborative conversation like those at Situation Tables. The variety of agency lenses on the same situation informs everyone's collection response to address an acutely elevated risk. When all community agencies recognize that truancy is a significant risk indicator, School Boards benefit as a result of a collaborative response to what has typically been seen as a school problem. For many at-risk youth, truancy is the tip of the iceberg indicator of other risk factors. Having students connected to appropriate services in a timely manner can positively impact student achievement. Situation Tables that include School Boards can connect students to appropriate social services in the community, which in turn can directly impact student attendance and student achievement.

Most School Boards, and most teachers and principals, are aware of many situations in which marginalized students face multiple risk factors. Schools struggle to mitigate these risk factors in isolation from community agencies. While many risk factors can be addressed internally through special education and mental health services, the Situation Table model provides new and improved opportunities for schools and community agencies, together, to address acutely elevated risks before a crisis occurs and before harm is caused to students, families or the community.

\section{ACKNOWLEDGMENTS}

The author would like to acknowledge the dedication of the members of Situation Table Northumberland and their continued working together. We are all part of these stories.

\section{CONFLICT OF INTEREST DISCLOSURES}

I have no conflicts of interest connected to the submission of this article.

\section{AUTHOR AFFILIATIONS}

*Resource Teacher [retired] for Safe Caring and Restorative Schools [retired from] Kawartha Pine Ridge District School Board, Peterborough, ON.

\section{REFERENCES}

Cameron, Kevin. Community threat and assessment protocol. Lethbridge, AB: Canadian Centre for Threat Assessment and Trauma Response; 2012 Retrieved May 1, 2016. Available from: http://kprschools.ca/content/ $\mathrm{dam} / \mathrm{kpr} /$ documents/CommunityThreatAssessmentProtocol.pdf

Community Mobilization Prince Albert (CMPA). (2013). The Hub \& COR model. Retrieved May 1, 2016. Available from: http://www.mobilizepa.ca/ who-we-are/the-hub-and-cor

McFee, D. R. \& Taylor, N.E. (2014). The Prince Albert Hub and the emergence of collaborative risk-driven community safety. Canadian Police College Discussion Paper Series. Ottawa: Canadian Police College.

Nilson, C. (2014). Risk-driven collaborative intervention: a preliminary impact assessment of the Prince Albert Hub model. Saskatoon, SK: University of Saskatchewan Centre for Forensic Behavioural Science and Justice 
Studies. Retrieved May 1, 2016. Available from: http://www.publicsafety.gc.ca/lbrr/archives/cnmcs-plcng/cn32162-eng.pdf

Russell, H.C. and Taylor, N. E. (2014). New Directions in Community Safety: consolidating lessons learned about risk and collaboration. Ontario
Working Group on Collaborative Risk-driven Community Safety. Toronto: Ontario Association of Chiefs of Police.

Wikipedia. (2016). Northumberland County, Ontario [online encyclopedia]. Retrieved May 1, 2016. Available from: https://en.wikipedia.org/wiki/ Northumberland_County,_Ontario 